\title{
TRANSFORMASI RELIEF CANDI PRAMBANAN DALAM KARYA TUBUH RITUS TUBUH OLEH ANGGONO KUSUMO WIBOWO
}

\author{
Siska Dwi Purwanti \\ Institut Seni Indonesia (ISI) Surakarta \\ Jln. Ki Hadjar Dewantara 19 Kentingan, Jebres, Surakarta 57126 \\ Daryono \\ Institut Seni Indonesia (ISI) Surakarta
}

\begin{abstract}
Transformation is a process of changing form, nature, and so on into new forms without leaving the values that existed in the previous culture. The process of transformation always produces elements of novelty, both in terms of style, taste, and meaning even at different levels of change. Transformation in art does not only occur in similar arts. Ancient relics, for example, as one form of art can be a starting point to be interpreted into visual expression in contemporary art, including dance. Tubuh Ritus Tubuh is one of the dance works which is a form of transformation of the Prambanan Temple relief. This study tries to uncover the allegations of the transformation of the Prambanan temple reliefs that can be observed on Tubuh Ritus Tubuh dance presentation. The problem of transformation is examined using the theory of change expressed by Lorens Bagus. The participatory research method carried out by the author is able to uncover the form of transformation found in certain parts of the dance presentation.
\end{abstract}

Keywords: transformation, relief, Prambanan Temple, Tubuh Ritus Tubuh.

\section{PENDAHULUAN}

Transformasi merupakan proses perubahan rupa, bentuk, sifat, dan sebagainya menjadi bentuk baru tanpa meninggalkan nilai-nilai yang ada dalam budaya sebelumnya. Proses transformasi tersebut selalu menghasilkan unsur-unsur kebaruan, baik dari aspek gaya, rasa, maupun maknanya walaupun pada tingkat perubahan yang tak sama (Sumaryono, 2003: 96).

Transformasi dalam suatu kebudayaan terjadi akibat saling pengaruh- mempengaruhi serta pencampuran unsur gaya kesenian dari dua kebudayaan. Transformasi dalam kesenian tidak hanya terjadi pada kesenian yang sejenis misalnya seni sastra yang berstransformasi menjadi seni pertunjukan, atau seni sastra yang bertransformasi menjadi seni pahat atau seni rupa. Salah satu wujud transformasi seni yang dilakukan seniman yaitu melalui objek seni rupa ke dalam bentuk seni tari. Peninggalan purbakala misalnya, sebagai salah satu wujud seni rupa ini bisa menjadi salah satu titik tolak untuk ditafsir ke dalam 
ekspresi visual dalam seni masa kini, termasuk ke dalam seni tari (Sedyawati, 2006: 295).

Tari merupakan sebuah pengalaman seni yang kreatif dimana dalam berkreasi, seorang seniman berarti melihat, menjadikan, dan mengerjakan sesuatu (Malraux dalam Hawkins, 1990: 15). Seorang koreografer harus menguasai masalah yang hendak diungkapkannya ke dalam karya tari. Hal tersebut berhubungan dengan tingkat kecerdasan, imajinasi, dan kreativitas penata tari tersebut. Bentuk kreativitas Anggono Kusumo Wibowo dalam karya Tubuh Ritus Tubuh yaitu proses mentransformasi relief Candi Prambanan ke dalam susunan karya Tubuh Ritus Tubuh itu sendiri. Selaku koreografer, Anggono mencoba untuk menggabungkan struktur relief pada Candi Prambanan dengan pengalamannya dalam pencarian motif gerak ceklek'an dalam tari Cakil yang kemudian ditransformasikan ke dalam karya tari. Penggunaan relief candi Prambanan sebagai acuan dalam membuat karya didasari oleh keindahan visual relief yang terdapat bentuk patahan-patahan serupa dengan bentuk ceklek'an dalam gerak Cakil. Ceklek'an berasal dari Bahasa Jawa "ceklek" yang artinya patah (Utomo, 2007: 68).

Istilah ceklek'an digunakan untuk sebutan yang merepresentasikan bentuk, proses, dan hasil kerja objek yang telah patah. Ceklek'an dalam tari Cakil menjadi istilah untuk menyebut nama suatu teknik gerak dan menjadi tolok ukur titik pencapaian kualitas kepenarian Cakil (Purwati, 2016: 569).

Anggono merupakan seniman tari di Surakarta yang terkenal dengan karakter Cakilnya. Oleh sebab itu, Anggono mencoba untuk mengkorelasikan ceklek'an hasil dari pecarianya dalam tari Cakil dengan ceklek'an yang ia temukan pada relief Candi Prambanan.

Berdasarkan pemaparan tersebut, karya karya Tubuh Ritus Tubuh menarik untuk dikaji karena karya tersebut mentransformasikan relief Candi Prambanan ke dalam bentuk karya tari dengan digabungkan konsep gerak ceklek'an pada tari Cakil sehingga menghasilkan ketubuhan dan motif-motif gerak yang lebih variatif. Oleh karena itu peneliti tertarik untuk mengkaji karya tersebut dengan judul Transformasi Relief Candi Prambanan dalam Karya Tubuh Ritus Tubuh Oleh Anggono Kusumo Wibowo.

\section{TRANSFORMASI RELIEF CANDI PRAMBANAN DALAM KARYA TUBUH RITUS TUBUH}

Penciptaan karya Tubuh Ritus Tubuh didasari oleh keinginan Anggono untuk menginterpretasikan konsep ceklek'an ke arah yang lebih luas. Ceklek'an yang biasanya ditemukan pada gerak tari Cakil kemudian dijadikan sebagai bahan eksplorasi gerak untuk sebuah karya yang nantinya akan dipentaskan dalam rangka ujian Tugas Akhir program Magister. Ide mengenai relief candi muncul setelah Anggono berkonsultasi dengan Bambang Suryono, salah satu pengajar pascasarjana Institut Seni Indonesia Surakarta. Anggono pada saat itu mencoba untuk melakukan riset lapangan mengenai relief candi, dan objek yang ia pilih adalah Candi Pambanan.

Keindahan relief Candi Prambanan telah memberikan daya imajinasi serta menginspirasi Anggono untuk bergelut dan berproses dalam mengeksplorasi tubuh 
sebagai penari. Pada konteks ini, Anggono tidak mencoba untuk menguak semua dari rentetan sejarah maupun filosofi yang ada di dalamnya. Anggono hanya mencoba masuk dalam satu wilayah bagian kecil dari keagungan keberadaan candi tersebut. Anggono mencoba untuk mempelajari, mengamati, dan memahami motif relief Candi Prambanan yang tampak secara fisik, untuk kemudian dijadikan referensi dalam pengolahan dan pengkayaan eksplorasi gerak tubuh penari. Melalui teknik tersebut, Anggono menemukan hal baru dalam risetnya mengenai gesture dan pose menari relief candi.

Hal tersebut menjadi konsep Anggono selanjutnya untuk mentransformasikan relief candi ke dalam tari sesuai dengan ide awalnya mengenai ceklek'an (Anggono Kusumo Wibowo, wawancara 11 November 2019).

Anggono merupakan salah satu seniman tari yang terkenal dengan karakter Cakilnya, oleh karena itu Anggono mencoba untuk menarik benang merah antara posepose pada relief candi dengan teknik gerak ceklek'an pada tari Cakil. Sehubungan dengan bentuk ceklek'an, Anggono memiliki pemahaman bahwa bentuk-bentuk relief pada Candi Prambanan juga dibuat sedemikian rupa sehingga membentuk kesan nyeklek atau patah yang sama sepertipada tubuh manusia, hanya saja visualisasi relief terbatas dalam dua dimensi (Anggono Kusumo Wibowo, wawancara 19 Maret 2019).

Alasan pemilihan Candi Prambanan sebagai objek yaitu dikarenakan adanya rangkaian cerita Ramayana yang utuh pada relief candi, sehingga nantinya dalam penggarapan maupun pertanggungjawaban karya sebagai bahan ujian akan lebih jelas benang merahnya antara konsep tari Jawa, cerita Ramayana yang digunakan sebagai motivasi, dan relief Candi Prambanan (Anggono Kusumo Wibowo, wawancara 30 Desember 2019).

Berdasarkan hasil pengamatan relief candi yang dilakukan oleh Anggono sendiri, disimpulkan bahwa secara fisik wujud relief (dua dimensi) mempunyai gesture yang lebih beragam, termasuk bentuk patahan atau tekukan sebagai salah satunya. Setelah melakukan pengamatan mendalam terhadap detail-detail bentuk relief, motif-motif lain yang tampak adalah pose yang menggambarkan sembahan, adegan perkelahian, peperangan, pose memegang senjata, dengan bentuk yang nampaknya cukup rumit jika diaplikasikan pada tubuh penari sebagai figur tiga dimensi (Wibowo, 2013: 119).

Anggono menggunakan pola dua dimensi pada relief Candi Prambanan sebagai pijakan penemuan eksplorasi gerak. Dukungan pengalaman empiris Anggono sebagai seniman tari menghasilkan pemikiran-pemikiran baru mengenai gerak yang lebih luas dan tidak hanya terpaut pada bentuk visual relief candi. (Anggono Kusumo Wibowo, wawancara 3 Desember 2019).

Berikut adalah langkah yang dilakukan Anggono dalam mentranformasikan relief Candi Prambanan ke dalam karya Tubuh Ritus Tubuh.

\section{Observasi Relief Candi Prambanan}

Proses observasi yang dilakukan Anggono bermula dari membaca relief-relief Candi Prambanan yang dilakukan selama tiga kali. Anggono membaca relief candi dengan metode bahasa rupa atau disebut sebagai Ruang Waktu Datar yang ditemukan 
oleh Primadi Tabrani, seorang Guru Besar Fakultas Seni Rupa ITB.

Membaca relief dengan metode ini lebih mementingkan gesture sehingga wujud tokoh dalam relief digambarkan secara lengkap dari kepala hingga kaki. Teori RWD yang dikemukakan oleh Tabrani sebagai berikut:

"Sistem RWD menggambar dari aneka arah, aneka jarak, dan aneka waktu. Yang digambar menjadi sekuen yang bisa terdiri dari sejumlah adegan dan objek-objek bergerak dalam ruang dan waktu. Media yang bisa bercerita adalah media bermatra waktu: musik, drama, tari, sastra. Karena sistem RWD memiliki matra waktu, maka ia juga dapat bercerita dengan memanfaatkan cara wimba dan tata ungkapnya, bukan keindahannya. RWD dengan bahasa rupanya memang lebih mementingkan pesannya, ceritanya, komunikasinya"' (Tabrani, 2005: 131).

Relief apabila diamati hanya sebagai wujud gambar diam layaknya hasil jepretan kamera. Akan tetapi berdasarkan teori Tabrani, relief menggunakan lapisan (layer) yang menunjukkan dimensi waktu, dan pergeseran tokoh sebagai sekuen. Lapis terdalam menunjukkan peristiwa yang terjadi terlebih dahulu (Tabrani, 2005: 67).

Berdasarkan hasil pengamatan Anggono terhadap gesture pada relief Candi Prambanan, ia memiliki ketertarikan terhadap salah satu panel relief yang terdapat tokoh Kalamarica. Tokoh Kalamarica pada relief Candi Prambanan terdapat pada panel ke-12 pilahan ke-2 sisi dalam Candi Siwa. Pada panel tersebut diceritakan bahwa Kalamarica yang menjelma menjadi kijang kencana untuk mengelabuhi Sinta atas perintah Rahwana dengan tujuan agar Rama mengejar kijang kencana untuk Sinta. Rama memanah kijang kencana, seketika Kalamarica keluar dari tubuh kijang dan menjerit kesakitan (Prasetya, 2004: 27).

\section{Eksplorasi Gerak}

Proses eksplorasi termasuk berpikir, berimajinasi, merasakan, dan merespon (Hawkins, dalam Hadi, 1990: 27). Proses eksplorasi yang dilakukan oleh Anggono misalnya, mengembangkan vokabuler gerak Cakil seperti sembahan, sabetan, candakan, dan sawuran; mengaplikasikan motif relief Candi Prambanan ke dalam tubuh penari; menggunakan bagian-bagian cerita Ramayana sebagai sumber motivasi dalam pencarian bentuk-bentuk gerak tari, misalnya pada adegan yang melibatkan penari perempuan, eksplorasi yang dilakukan mengolah tokoh perempuan dalam cerita Ramayana seperti Sarpakenaka dan Sinta.

Ketiga rangkaian proses tersebut merupakan bagian dari inovasi Anggono dalam menggabungkan ide mengenai relief candi dengan pengalaman empirisnya. Berkaitan dengan hal tersebut, Humardani mengatakan bahwa kesenian bukan hanya soal menggarap medium melainkan juga terwujud dalam pengalaman yang diungkapkan dengan teknik baru (Humardani, 68).

Pengalaman Anggono sebagai penari Cakil kemudian membawa Anggono untuk mengekssplorasi teknik gerak Cakil dengan dipadukan poses-pose relief pada Candi Prambanan. Sehingga pada akhirnya Anggono mampu menghasilkan wujud tarian hasil transformasi reliefyang merupakan ciri khas Anggono sendiri. 
Pertunjukan karya Tubuh Ritus Tubuh di panggung Teater Besar Institut Seni Indonesia Surakarta yang berdurasi 45 menit terangkum dalam video dokumentasi Laboratorium Pandang Dengar Institut Seni Indonesia Surakarta. Melalui video dokumentasi tersebut, penulis berhasil membuka imajinasi sebagai penghayat dan menginterpretasikan maksud Anggono untuk menstransformasikan relief Candi Prambanan ke dalam karya Tubuh Ritus Tubuh. Hasil interpretasi penulis didukung dengan konsep perubahan yang dikemukakan oleh Lorens Bagus, di mana sesuatu yang berubah menjadi bentuk baru tidak akan mengubah esensi asli secara kuantitatif, mengalami perubahan tempat, dan mengalami transisi dari suatu kemungkinan ke sebuah aktualitas (2000: 86).

Hasil secara keseluruhan dari proses transformasi yang dilakukan Anggono selaku koreografer dalam karya Tubuh Ritus Tubuh yaitu menemukan identitas gerak, konsep ceklek'an yang tidak hanya dilakukan pada lengan seperti pada tari Cakil akan tetapi bisa diartikan sebagai patahan-patahan dalam beberapa bagian tubuh seperti lengan, kaki, dan tolehan kepala, dan teknik melakukan gerak dalam ruang.

Wujud transformasi relief candi dalam karya Tubuh Ritus Tubuh pada akhirnya tidak digambarkan secara wantah atau sama persis dengan wujud aslinya, akan tetapi mampu memberikan gambaran lain tentang ide relief candi dalam karya tari. Wujud transformasi relief candi ke dalam tari yang dilakukan oleh Anggono pada dasarnya merupakan salah satu bentuk perubahan vertikal, di mana terjadi perubahan dari relief
Candi Prambanan yang muncul pada abad ke-9 kemudian menjadi sebuah karya tari pada tahun 2012 yang hanya mengambil esensi terkecil dari kemegahan candi. Hal tersebut juga dikatakan oleh Timbul Haryono "Transformasi merupakan bagian dari perubahan, sedangkan perubahan itu terbagi menjadi dua yaitu perubahan secara vertikal dan horisontal.

Perubahan secara vertikal umum terjadi di lingkup kebudayaan, di mana suatu budaya tentunya akan terus berubah dan berkembang dari tahun ke tahun, era ke era, misalnya dari relief candi bertransformasi ke wayang, lukisan, patung, dan tari. Untuk perubahan horizontal adalah perubahan yang terjadi apabila berasal dari kebudayaan asing, misalnya relief candi di India yang dibawa ke Indonesia kemudian disesuaikan dengan kebudayaan lokal sehingga menghasilkan budaya yang berbeda" (Timbul Haryono, wawancara 12 Januari 2020).

Transformasi dalam hal ini apabila disesuaikan dengan konsep perubahan yang dikemukakan oleh Lorens Bagus, maka dapat disimpulkan bahwa di dalam prosesnya, karya Tubuh Ritus Tubuh tidak mempengaruhi esensi asli Candi Prambanan. Wujud transformasinya tentu telah mengalami perubahan tempat, di mana awalnya objek berada di kompleks Candi Prambanan kemudian esensi yang ada pada relief candi di bawa ke Surakarta untuk digarap menjadi karya tari. Selain itu juga terdapat proses transisi dari wujud relief candi ke bentuk baru yaitu karya Tubuh Ritus Tubuh. 


\section{BENTUK SAJIAN KARYA TUBUH RITUS TUBUH}

Menurut Hadi, pendekatan "teks" atau menganalisis secara fisik suatu karya tari dilakukan dengan menganalisis bentuk, teknik, dan gaya secara koreografis; analisis secara struktural; dan analisis simbolik (Hadi, 2007: 21). Berikut akan dijabarkan analisis bentuk karya Tubuh Ritus Tubuh.

\section{ANALISIS KOREOGRAFIS}

Menganalisis suatu karya tari secara koreografis berarti mendiskripsikan atau mencatat secara analitis fenomena tari yang nampak dari sisi bentuk luarnya saja. Konsep koreografis untuk menganalisis sebuah tari dapat dilakukan dengan telaah bentuk geraknya, teknik geraknya, dan gaya geraknya (Hadi, 2007: 23-24).

\section{Analisis bentuk gerak}

Pengertian bentuk adalah wujud yang merupakan hasil dari berbagai elemen tari yaitu gerak, ruang, dan waktu yang membentuk satu kesatuan untuk mencapai vitalitas estetis. Pemahaman analisis bentuk gerak adalah menganalisis proses mewujudkan atau mengembangkan suatu bentuk dengan berbagai pertimbangan prinsip-prinsip bentuk untuk kemudian menjadi wujud gerak tari (Hadi, 2007: 24-25). Prinsip-prinsip bentuk yang perlu dianalisis meliputi kesatuan, variasi, repetisi, transisi, rangkaian, dan klimaks (Hadi dalam Hadi, 2007: 25).

\section{a. Kesatuan (Unity)}

Kesatuan mengandung pengertian menjadi satu yang utuh (Hadi, 2007: 25). Kesatuan dalam hal ini tidak hanya dalam memperagakan gerak yang sama. Hasil kesatuan yang utuh dari gerak, ruang, dan waktu yang hadir dalam tari secara bersamaan mencapai vitalitas estetis yang apabila tanpa kesatuan itu tidak akan terwujud. Pada tari kelompok, konsep kesatuan dapat dilihat apabila penari melakukan gerakan yang sama, dalam ruang yang sama, dan dengan tempo yang sama. Selain itu kesatuan juga dapat dilihat apabila penari melakukan pola gerak yang berbeda dalam satu ruang sama, meski dengan tempo yang berbeda.

\section{b. Variasi}

Variasi merupakan prinsip bentuk, di mana tari sebagai karya kreatif harus memahami yang serba "baru" (Hadi, 2007: 26). Pada proses pembentukan gerak tari, koreografer perlu memperhatikan nilai-nilai kebaruan tersebut. Karya Tubuh Ritus Tubuh mengedepankan pola-pola gerak Cakil yang telah mengalami pengembangan dan pembaruan. Hal tersebut menjadikan adanya daya variasi dalam sajian karyanya. Selain itu, penggabungan pola-pola gerak flowing dan gerak-gerak tegas dalam karya Tubuh Ritus Tubuh mendukung adanya daya variasi dalam sajiannya.

\section{c. Repetisi/ Pengulangan}

Repetisi sangat berarti dalam sebuah karya tari karena sifat tari yang hanya sesaat (Hadi, 2007: 26).

Tanpa adanya repetisi, suatu tangkapan inderawi penglihatan terhadap gerak akan cepat hilang dan tergantikan dengan gerak baru dalam karya tersebut. Pengulangan gerak dalam suatu karya tari dapat menjadi salah satu aspek dalam menentukan ciri khas gerak dalam karya tersebut. Menurut Hawkins, pengulangan 
tidak hanya digunakan untuk menyampaikan ide, akan tetapi memberi kesempatan penonton untuk menyerap bentuk gerak (Hawkins dalam Hadi, 2007: 27).

Makna lain mengenai pengulangan yaitu bahwa pengulangan dapat dilakukan untuk memberikan jeda "pengembangan" atau "variasi" agar tidak selalu memperlihatkan kebaruan (Hadi, 2007: 27). Karya Tubuh Ritus Tubuh terdapat beberapa pengulangan gerak yang menjadikan gerak tersebut ciri dalam karya, salah satunya yaitu pengulangan gerak yang merupakan pengembangan dari teknik gerak ceklek'an, tujuannya adalah untuk memberi tahu penonton bahwa karya Tubuh Ritus Tubuh merupakan hasil dari transformasi relief candi yang digabungkan dengan teknik gerak ceklek'an tersebut (Anggono Kusumo Wibowo, wawancara 18 Februari 2020).

Pengulangan lain dalam sajian karya Tubuh Ritus Tubuh yaitu pegulangan gerakgerak flowing yang ada pada adegan 2 tunggal dan adegan 5 tunggal. Pengulangan tersebut memberi jeda antara gerak-gerak tegas dan bentuk-bentuk pembaruan ceklek'an yang sering muncul dalam sajian karya Tubuh Ritus Tubuh.

\section{d. Transisi}

Transisi dapat diartikan sebagai sambungan dari gerak satu ke gerak yang lain dengan terampil, sehingga bentuk gerak menjadi lebih efektif menciptakan kesatuan atau keutuhan (Hadi, 2007: 27). Proses transisi dalam tari memiliki peranan "pengikat" yang sangat penting sehingga dalam rangkaiannya mampu memperlihatkan kelancaran gerak.

Karya Tubuh Ritus Tubuh menggunakan berbagai jenis gerak transisi, yaitu berlari, melompat, berjalan mengalun, dan diam.

\section{Analisis teknik gerak}

Teknik diartikan sebagai seluruh proses baik fisik maupun mental yang memungkinkan penari mewujudkan estetisnya dalam sebuah komposisi atau koreografi sebagaimana juga keterampilan untuk melakukannya (Hadi, 2007: 24). Analisis mengenai teknik gerak berhubungan dengan gerak itu sendiri sebagai media ungkap sajian tari dan pengalaman ketubuhan penari sebagai instrument dalam mewujudkan bentuk tari.

Gerak dalam karya Tubuh Ritus Tubuh dirangkai dengan menggunakan konsep tari Jawa baik secara struktur garap maupun teknik ketubuhan penari. Anggono menggunakan struktur maju beksan, beksan, dan mundur beksan sebagai alur garap karya Tubuh Ritus Tubuh. Hal ini berhubungan dengan alur dramatik pertunjukan karya Tubuh Ritus Tubuh di mana penggunaan struktur garap tari Jawa dapat mempermudah dalam menentukan permulaan, klimaks, dan penyelesaian.

\section{Gaya gerak}

Pengertian gaya atau style dalam pemahaman ini lebih mengarah pada konteks ciri khas atau corak yang terdapat pada bentuk dan teknik gerak, terutama menyangkut pembawaan pribadi atau individual, maupun ciri sosial budaya yang melatarbelakangi kehadiran bentuk dan teknik tariitu (Hadi, 2007: 33), sehingga dapat disimpulkan bahwa ciri khas gaya juga berkaitan dengan latar belakang koreografer.

Pengalaman Anggono sebagai seniman tari tradisi khususnya gaya 
Surakarta menjadi salah satu kunci dalam pencarian gerak karya Tubuh Ritus Tubuh. Karakter Cakil yang melekat pada tubuh Anggono dimanfaatkan sebagai ciri khas dalam setiap pembentukan gerak. Oleh karena itu, pada setiap karyanya Anggono memiliki gayanya sendiri yang khas yaitu

a. Menggunakan pola-pola ceklek'an Cakil yang dikembangkan sesuai konsep dan tema tari dalam karyanya;

b. Mengutamakan ketubuhan baik dari segi kekuatan maupun keseimbangan tubuh dalam bergerak;

c. Memanfaatkan cerita Ramayana atau Mahabharata sebagai motivasi dalam memberikan vokabuler gerak.

Gaya gerak Anggono yang nampak pada karya karya Tubuh Ritus Tubuh yaitu pola-pola gerak yang terkesan tegas, sebagai wujud dari patahan pose-pose relief Candi Prambanan.

\section{Analisis jumlah penari}

Penetapan jumlah penari baik gasal maupun genap, tergantung dengan maksud garapan koreografinya, atau kehendak koreografer tari tersebut. Komposisi kelompok dengan penari gasal maupun genap memberikan alternative yang lebih leluasa bagi koreografer (Hadi, 2007: 45).

Karya Tubuh Ritus Tubuh menggunakan sembilan orang penari dengan delapan penari laki-laki dan satu orang perempuan.

\section{Analisis jenis kelamin dan postur tubuh}

Peran penari dalam sajian pertunjukan nonliterel tidak begitu mengikat, melainkan lebih mementingkan komposisi kelompok yang berkaitan dengan keruangan. Oleh karena itu tarian nonliterel lebih menguntungkan apabila menggunakan kelompok penari yang sama baik jenis kelamin maupun postur tubuhnya. Akan tetapi, karya Tubuh Ritus Tubuh ini menggunakan satu penari perempuan dengan delapan penari laki-laki. Pemilihan penari perempuan yaitu brdasarkan ketubuhan yang pada saat itu Agung Wening sebagai satu-satunya penari perempuan adalah juga penari Cakil yang tentunya memiliki pengalaman ketubuhan yang sama seperti penari laki-laki (Anggono Kusumo Wibowo, wawancara 23 Agustus 2019).

Selain faktor ketubuhan, satu penari perempuan juga dimaksudkan untuk memberi kemudahan penari lain dalam menangkap motivasi yang disampaikan oleh Anggono, yakni motvasi gerak yang terinspirasi oleh cerita Ramayana.

\section{Analisis struktur ruangan}

Pengertian ruang atau area adalah lantai tiga dimensi yang di dalamnya seorang penari dapat mencipta suatu imaji yang dinamis, yaitu perincian komponenkomponen yang membawa banyak kemungkinan untuk mengeksplor gerak (Hadi, 2007: 54). Seorang penari dengan keterampilan geraknya dapat membuat ilusiilusi sehingga ruang menjadi fleksibel dan luar biasa keberadaannya. Penonton benar-benar melihat aspek-aspek ruang karena gerakan tubuh secara keseluruhan, yaitu dengan adanya bentuk, arah, dan dimensi (Hadi, 2003: 24-29).

Karya Tubuh Ritus Tubuh di pentaskan pada ruang proscenium Teater Besar Institut Seni Indonesia Surakarta dengan luas $9 \times 5$ meter. Ruang proscenium disetting 
menggunakan rangkaian bamboo sepanjang $7 \times 7$ meter yang dirangkai vertikal horizontal dan ditempatkan pada bagian tengah panggung. Selain tu, pada bagian depan juga dipasang bidang miring dengan pola abstrak atau tak beraturan. Menurut Supriyadi selaku tim artistik yang menata panggung, tidak ada makna tertentu dalam penataan ruang yang demikian, melainkan hanya menyesuaikan dengan konsep pengkarya mengenai sajian karya tari yang menuntut keseimbangan dan kekuatan tubuh.

\section{Analisis struktur dramatik}

Analisis struktur dramatik adalah mengidentifikasi bahwa sebuah pertunjukan tari merupakan rangkaian kejadian yang dimulai dari permulaan, perkembangan, klimaks, dan penyelesaian. Koreografi kelompok yang bersifat nonliterel umumnya memiliki satu klimaks yang digambarkan dengan skema kerucut tunggal (Hadi, 2005: 77).

Karya Tubuh Ritus Tubuh terbagi menjadi lima adegan, yang dimulai dari adegan permulaan, dilanjutkan dengan perkembangan hingga klimaks, lalu penyelesaian sampai dengan akhir adegan. Kelima adegan tersebut memiliki perbedaan dalam pola gerak, permainan dinamika dan tempo sehingga terangkai menjadi satu alur dramatic yang runtut.

\section{TATA TEKNIK PENTAS}

Analisa tata teknik pentas sebagai salah satu bagian dari analisis koreografis merupakan aspek pendukung kehadiran sebuah pertunjukan tari. Analisis ini meliputi tata rias busana dan tata panggung dan cahaya.

\section{a. Tata busana}

Menurut Soedarsono, dalam lingkup dunia tari kostum dapat dikatakan sebagai segala sesuatu yang menutupi tubuh penari (1978: 34). Kostum atau busana tari yang dipergunakan untuk melukiskan sesuatu oleh penciptanya dan dipakai oleh penarinya, tidak dapat melepaskan pemilihan dan nilai dari warna dan gari bentuk yang ditambah dengan hiasan yang berbentuk ukiran dan lain-lain (Kussudiardja, 1992: 64).

Penggunaan warna merah pada busana karya Tubuh Ritus Tubuh didasari oleh pemaknaan kesan kuat pada warna merah itu sendiri yang sesuai dengan tema karya, sehingga terdapat keselarasan antara kostum dan keseluruhan karya. Kostum dipilih dengan menyesuaikan bentuk tubuh yakni berupa celana short merah ketat dan sport bra berwarna merah untuk menari perempuan. Pemilihan kostum yang sederhana dan minimalis memugkinkan penari untuk lebih leluasa dalam bergerak pada ruang panggung yang demikian. Selain itu, ketubuhan penari juga dapat dilihat dengan jelas oleh penonton.

\section{b. Tata panggung dan tata cahaya}

Ruang adalah sesuatu yang tidak bergerak dan diam sampai gerakan yang terjadi di dalam ruang mengintroduksi waktu (Soedarsono, 1978: 49). Pertunjukan karya Karya Tubuh Ritus Tubuh dilaksanakan di panggung proscenium Teater Besar

Institut Seni Indonesia Surakarta dengan tambahan setting yang abstrak. Setting yang dimaksud yaitu tambahan bidang miring di bagian depan panggung, trampolin di bagian kanan panggung, bidang datar tinggi di bagian kanan panggung, dan rangkaian bambu yang disusun horizontal 
vertikal di bagian belakang panggung. Panggung yang didesain demikian menunjang eksplorasi gerak masing-masing penari untuk mengembangkan gerak-gerak yangtelah disusun kemudian ditempatkan pada bidang panggung yang ekstrim sehingga teknik kekuatan dan keseimbangan dapat dicapai dengan baik. Lighting atau tata cahaya dalam pertunjukan Karya Tubuh Ritus Tubuh lebih banyak menggunakan lampu general kuning dan beberapa lampu spot pada adegan duet dan tunggal. Hal tersebut bertujuan untuk memperjelas kehadiran penari dalam ruang dan memberjelas struktur ruang.

\section{PENUTUP}

Transformasi dalam karya Tubuh Ritus Tubuh oleh Anggono tidak sepenuhnya terwujud secara verbal, akan tetapi mengalami beberapa perubahan akibat dari latar belakang Anggono selaku koreografer. Selain itu, apa yang terlihat dalam sajian karya yaitu tidak hanya transformasi secara konseptual di mana Anggono melihat wujud relief candi kemudian menjadikan relief sebagai konsep awal dalam menciptakan karya, akan tetapijuga transformasi nilai dan imajinasi yang dapat ditangkap oleh pengamat, sehingga dari hasil pengamatan dan observasi yang dilakukan penulis dapat disimpulkan bahwa transformasi yang terjadi pada karya Tubuh Ritus Tubuh yaitu transformasi kolektif, yang meliputi proses transformasi konseptual oleh koreografer dan transformasi imajinasi oleh pengamat berdasarkan observasi dan pengamatan terhadap wujud karya tari.

Pada akhirnya apabila diamati, sajian karya Tubuh Ritus Tubuh menyimpan nilai keindahan Candi Prambanan yang telah dirangkum menjadi sebuah karya tari berdurasi 45 menit dengan dukungan berbagai faktor internal dan eksternal dari pengkarya maupun penari sehingga menjadikan karya tari yang kaya akan interpretasi mengenai Candi Prambanan.

\section{KEPUSTAKAAN}

Agung Wening Titis Purwati. 2016. “Ceklek'an Sebagai Garap Gerak dalam Kepenarian Cakil Gaya Surakarta," Terob, Jurnal Pengkajian dan Penciptaan Seni Vol. 6 No. 2 (April 2016): 563-573.

Anggono Kusumo Wibowo. 2013. “Dari Relief Candi Menuju Karya Tari: Sebuah Catatan Kreatif," Greget, Jurnal Pengetahuan dan Penciptaan Tari Vol. 12 No. 2 (Desember 2013): 109-127.

Bagus, Lorens. 2000. Kamus Filsafat. Jakarta: Gramedia.

Bandem, I Made. 1996. Etnologi Tari Bali. Yogyakarta: Kanisius.

Hadi, Sumandyo. 2003. Aspek-Aspek Dasar Koreografi Kelompok. Yogyakarta: Penerbit Élkaphi.

2007. Kajian Tari Teks dan

Konteks. Yogyakarta: ISI Press.

2017. Koreografi; Bentuk, Teknik, dan Isi. Yogyakarta: Cipta Media.

Haryono, Timbul. 2008. Seni Pertunjukan dan Seni Rupa dalam Perspektif Arkeologi Seni. Surakarta: ISI Press. 
. 2012. "Ramayana di Indonesia Sebuah Perspektif Arkeologi dan Sejarah" dalam Hermanu (ed). Relief Ramayana Prambanan, 19262012. Yogyakarta: Bentara Budaya Yogyakarta.

Hawkins, Alma M. 1990. Mencipta Lewat Tari, dialihbahasakan oleh Y. Sumandyo Hadi. Yogyakarta: ISI Press.
Sastro Utomo, Sutrisno. 2007. Kamus Lengkap Jawa-Indonesia. Yogyakarta: Penerbit Kanisius.

Sedyawati, Edi. 2006. Budaya Indonesia; Kajian Arkeologi, Seni, dan Sejarah. Jakarta: PT Rajagrafindo Persada.

Sumaryono. 2003. Restorasi Seni Tari dan Transformasi Budaya. Yogyakarta: Lembaga Kajian Pendidikan dan Humaniora Indonesia. 